\title{
Impactos do Conhecimento das Ciências Naturais para o Desempenho no ENEM: Considerações sobre a Desigualdade Científico-tecnológica para a Justiça Social
}

Impact of Knowledge of Natural Sciences on ENEM Performance: Considerations about Scientific and Technological Inequality to Social Justice

\author{
Diego Navarro, ${ }^{(1)}$ Matheus lanello, ${ }^{(1)}$ Felipe Muneratto, ${ }^{(1)}$ Graciella Watanabe
}

\begin{abstract}
Palavras-chave Resumo Partindo da perspectiva das sociologias da educação e da Desigualdade; ciência, o presente artigo tem como objetivos: analisar o desempenho Exame Nacional de estudantes em ciências da natureza comparativamente a outras do Ensino Médio; áreas do conhecimento do Exame Nacional do Ensino Médio; Sociologia da analisar o desempenho dos candidatos de instituições públicas e Educação; privadas; apresentar considerações preliminares que indicam como a Ciências da presença de laboratórios científicos nas escolas podem dar indícios de Natureza. melhoria no desempenho. Avança-se o debate mobilizando o conceito de desigualdade científico-tecnológica e boa vontade cultural, para propor uma interpretação dos dados que permita a comparação entre desempenho de alunos nessas diferentes redes de ensino no que se refere ao conhecimento das ciências da natureza. A seleção dos dados reporta-se aos microdados do Exame Nacional do Ensino Médio (ENEM) - edição 2017 - em que foram investigados os estudantes matriculados no terceiro ano do ensino médio, que acertam na faixa de 600 a 1000 pontos em ciências da natureza, de modo a comparar esses resultados com as outras áreas do saber. Os dados mostram que alunos das escolas públicas estaduais possuem um desempenho entre áreas proporcionalmente mais significativo nas ditas de exatas (e em redação) do que alunos das escolas privadas. Ainda, é encontrada nessa faixa de desempenho uma baixa representatividade dos alunos das escolas públicas em oposição à rede privada, que pode ser interpretada como uma característica marcadamente da desigualdade social e educacional no país.
\end{abstract}

Submetido em 26 de outubro de 2020 Aceito para publicação em 23 de março de 2021

Publicado em 13 de outubro de 2021 
Keywords Abstract This paper sets out from the perspective sociology of Inequality; education and sociology of science, aiming: analyze the performance National High of students in nature sciences compared to other areas of knowledge in School Exam; the National High School Exam; analyze the performance of candidates Sociology of from public schools and private schools; present preliminary Education; considerations that indicate how the presence of scientific laboratories Natural Sciences. in schools show some evidence of improvement in performance. The debate goes through by mobilizing the concept of scientific inequality and cultural goodwill to propose an interpretation of data that allows a comparison between the performance in natural sciences of students from several school systems by comparative analysis among public and private schools. The data selection it reports on the microdata of the National High School Exam (ENEM) - 2017 edition - which was investigated the results of students from the final year (senior year) who scores between 600 and 1000 points in natural sciences in order to compare these results with other areas of knowledge. The data show that students from public schools have proportionally more significant performance (between fields of knowledge) in hard sciences (and writing) than students from private schools. In addition, it is found in this range of score of the analysis a disproportion of representativeness of students from public schools on objection of private ones that can be interpreted as a marked characteristic of social and educational inequality in the country.

\section{Introdução}

O problema da desigualdade social tem marcado o trabalho de pesquisadores em diferentes subcampos da educação (Peregrino, 2010; Peugny, 2014). A análise educacional que parte dessa perspectiva visa, dentre distintas categorias de análise, como diferenças econômicas, étnicas e de gênero, indicar em que medida as distinções sociais e culturais trazidas por alunos para sala de aula podem impactar na aprendizagem e nas interações com outros atores sociais como professores, coordenadores e a comunidade escolar (Setton, 2011). Ao passo que tais pesquisas tratam esses aspectos, elas viabilizam debates para além das aprendizagens na sala de aula e permitem abranger tais discussões sobre o futuro dos jovens estudantes e como suas escolhas profissionais não condizem, exclusivamente, pelo desejo pessoal, mas podem também estar associadas ao que na literatura é conhecida como "escolha relacionada ao destino" (Rocha \& Perosa, 2008). Essa perspectiva está fortemente influenciada, ainda que não unicamente, ao que já apontava Bourdieu e Passeron (2013) sobre o destino reservado socialmente à determinados grupos sociais.

No caso brasileiro, a complexidade do problema se dá pela dimensão territorial e pelas distinções sociais e culturais que são inevitáveis dentro de um país com geografia 
continental (Gramani, 2017). Para se ter um panorama do que fala Gramani (2017) pode-se mobilizar os dados de 2015 da Pesquisa Nacional por amostra de Domicílios (PNAD/IBGE, 2015), que indicava que a população de jovens entre 15 e 17 anos "era de 10.637.610; e a taxa de escolarização era de 85\%. Entre estes(as) jovens, 1.593.141 estavam fora da escola; 1.863 .158 ainda se encontravam no ensino fundamental e 83.633 são analfabetas/os" (Krawczyk \& Silva, 2017, p. 14). Ao focar no Ensino Médio, em 2016, a taxa de matrículas dessa fase do ensino em relação à Educação Básica brasileira como um todo era de 16,7\%, sendo 8.133.040 estudantes matriculados em 28,4 mil escolas (Krawczyk \& Silva, 2017).

Em um comparativo, exclusivamente quantitativo, com a Finlândia e seu sistema de ensino (Bastos, 2017), têm-se 93\% de alunos que concluem o ensino secundário em comparativo aos 5,5 milhões de habitantes em 2017 naquele país, enquanto, o Brasil, com 209,3 milhões de habitantes no mesmo ano, possuía a taxa de abandono em torno de $6 \%$, ou seja, dos alunos que entram no Ensino Médio, têm-se 94\% que o concluem (Abrinq, 2017). Ainda que tal dado possa parecer alentador, é necessário indicar que há muitos jovens entre 15 e 17 anos fora da escola. Ou seja, somente 68\% dessa população entrou para o Ensino Médio (IBGE, 2017). Esse debate, em termos gerais, já apresenta uma diferença na escala nacional que faz da educação científica brasileira uma área relativamente complexa e distinta de outros países ${ }^{1}$ (Marguti et al., 2017). Ainda,

Apesar da melhoria dos indicadores de acesso e permanência na escola nos últimos 20 anos no país, a garantia do direito ao Ensino Médio segue como uma questão não resolvida pelas políticas públicas educacionais, persistindo o desafio da sua universalização, com qualidade social (Krawczyk \& Silva, 2017, p. 14).

Se, contudo, diante dos desafios impostos, os alunos das escolas públicas iniciam o processo de adentrar o ensino superior, a escolha feita pela carreira profissional ou o futuro acadêmico nem sempre é direto. Estudos mostram que essa escolha perpassa diferentes experiências sociais e culturais que permeiam a dimensão de uma possível “escolha pessoal” (Duru-Bellat \& Van Zanten, 2009; Rocha \& Perosa, 2008). Ao optar por fazer um curso no ensino superior, alunos do Ensino Médio ${ }^{2}$ mobilizam questões como o status social da profissão ou ainda, encontram-se casos em que, por vias implícitas associadas às violências simbólicas, levam a situações que direcionam tal escolha por critérios pragmáticos, onde se observa que "grupos socialmente desfavorecidos poderiam estar sendo desviados para o ensino superior periférico, desse modo reforçando a estratificação do setor e a diferenciação social" (Morley, 2013, p. 424).

Em termos econômicos, Pires (2015) aponta que alunos provindos de famílias com renda superior a vinte salários mínimos possuem melhor desempenho nas avaliações em larga escala como o ENEM, tendo, inclusive, maior influência em termos de correlação à formação educacional da figura paterna. Tais debates avançam através

1 Em termos populacionais, a Finlândia possui 2,6\% dos habitantes do Brasil (Marguti, Costa \& Pinto, 2017).

2 Nesse artigo, serão analisados alunos do terceiro ano do ensino médio, ainda que se reconheça que um número expressivo de candidatos ao ensino superior já finalizou essa etapa de sua formação. 
de estudos dessas avaliações, onde as desigualdades se mostram um fator histórico que vêm impactando na entrada no ensino superior dos representantes das camadas socioeconômicas desfavorecidas (Silva et al., 2011; Costa-Beber et al., 2014).

Alguns autores (Archer et al., 2015) argumentam que a aprendizagem científica também possui sua faceta social e contribui para esse processo de exclusão social. Seus estudos têm mostrado que a existência de um capital, aos moldes do capital cultural (Bourdieu \& Passeron, 2013), associado à ciência se torna proeminente nos estudantes ingleses que aspiram às carreiras científicas ou estudos voltados para as exatas. No Brasil, alguns trabalhos têm mobilizado essa discussão, onde elementos sociais influenciam a formação e escolha profissional dos candidatos e participantes do espaço universitário brasileiro (Kleinke, 2017; Nascimento et al., 2019; Lima Junior et al., 2013; Silva \& Barbosa; 2019). Contudo, uma questão permanece estanque a tal debate: De que maneira as ciências naturais, como conhecimento escolar, influenciam (ou não) o ingresso de estudantes no ensino superior brasileiro?

Diante do desafio em responder uma parte dessa complexa pergunta, essa pesquisa pretende analisar o impacto do conhecimento científico, comparativamente às outras áreas do conhecimento do Exame Nacional do Ensino Médio, na nota final dos alunos que participaram dos dois dias de provas da edição de 2017 do ENEM e obtiveram resultados superiores a $600^{3}$ pontos em Ciências da Natureza ${ }^{4}$. Essa avaliação possui papel fundamental no acesso ao ensino superior, ao mesmo tempo que sua análise visa compreender o nível conceitual e procedimental das ciências naturais pelos alunos. Portanto, apresentam-se como objetivos desse trabalho: (1) Analisar o desempenho de estudantes em ciências da natureza comparativamente a outras áreas do conhecimento no ENEM; (2) Analisar, de modo a contrapor tais notas, o desempenho dos candidatos entre instituições públicas e privadas; e (3) Apresentar considerações preliminares dos resultados que indicam como a presença de laboratórios científicos nas escolas podem dar indícios de melhoria no desempenho dos pesquisados.

Em suma, buscar-se-á discutir em que medida o conhecimento científico possui papel importante na formação dos alunos oriundos do Ensino Médio nas escolas públicas, assim como, quais as representações desses estudantes nas faixas mais elevadas de pontuação do ENEM comparativamente aos alunos do ensino privado. Pretendese com esse debate defender o ensino de ciências da natureza nas salas de aula como fator determinante para traçar as trajetórias históricas e futuras dos alunos menos privilegiados econômica e culturalmente.

3 Os alunos que atingem tal resultado possuem chances razoáveis de concorrer a vagas no ensino superior público, portanto, sendo uma pontuação base para reconhecer que tais alunos obtiveram sucesso no ENEM.

4 No presente artigo foi utilizado o termo "ciências da natureza" para se referir ao conhecimento das ciências física, química e biologia enquanto "Ciências da Natureza" para representar a área do conhecimento do ENEM. 


\section{A Desigualdade Científico-Tecnológica}

Para pensar as desigualdades social e educacional, podemos recorrer às visões econômicas que promoverem papel crucial nos modos como se comportam as práticas culturais dos últimos 40 anos no Brasil. Libâneo (2012) argumenta que a visão importada do lema "educação para todos" tem sua raiz nos documentos e discursos patrocinados pelo Banco Mundial nos anos 90, cuja visão da escola solidária aos mais pobres ganhou contornos perversos de uma educação cada vez menos comprometida com o ensino da ciência e da cultura como condição para o desenvolvimento crítico cognitivo, afetivo e moral dos alunos. Essa "invasão neoliberal" em nossa sociedade (globalizada) gerou uma nova percepção, também, do que seria saber sobre ciência. Tal entendimento foi marcado pelo consumo dos produtos gerados em diferentes países, em diferentes situações (des)humanizadas e em condições econômicas distintas. Assim, o conhecimento dos processos acabou sendo deixado de lado em oposição à aquisição de bens materiais e pouco dos bens culturais (Cunningham, 2002).

Tais relações pragmáticas com o conhecimento, ou seja, embasadas em consumo dos objetos de forma acrítica, evitam mobilizar reflexões analíticas sobre os aparatos tecnológicos e a não-neutralidade da ciência (Delizoicov \& Auler, 2011). A ciência, assim, se torna um mero instrumento "mediador" entre a necessidade e o bem-estar, sem qualquer vínculo com a dimensão de acesso à sua produção. Ou seja, a "perda do sentido de ciência", como bem simbólico, gera a "perda do sentido da aprendizagem científica" na vida escolar dos estudantes. A longo prazo, essa apatia em relação às ciências da natureza leva a afastamentos desse conhecimento da vida cotidiana.

Para melhor compreensão dessas dimensões faz-se necessário mobilizar dois arcabouços teóricos. Pierre Bourdieu (1994) que reconhece que bens simbólicos possuem papel fundamental nas distinções sociais e, complementarmente, Charles Tilly (2006) que advoga que a ciência se tornou, para além de uma aquisição do tipo cultural, um dos bens mais importantes para definir as desigualdades sociais, cunhando-a sob o termo "desigualdade científico-tecnológica". Para compreender de que maneira a ciência se tornou um "bem simbólico" (Bourdieu, 1994) que, posteriormente, caracterizou-se como um dos pilares da desigualdade social, é relevante compreender as fronteiras dessa reflexão que permeará o debate dos dados.

A ciência, segundo Bourdieu (2001), divide-se entre conhecimento puro e jogo político. Nesse contexto, no campo científico (espaço de lutas), o saber da ciência natural possui papel importante como elemento que define as regras básicas do jogo nesse espaço social (Bourdieu, 2001; Sapiro, 2004). A luta pela autoridade científica se pauta em duas lógicas centrais, opositoras nos campos, e que são derivadas, em partes, dos capitais científicos institucional (político e temporal) e puro (prestígio) (Montagner \& Montagner, 2011).

Em outras palavras, para ser aceito nesse campo é preciso que se tenha algo valioso, ou seja, o instrumento simbólico valorizado pelos cientistas e reconhecido entre seus pares: o saber científico (Bourdieu, 2003; Gurgel \& Watanabe, 2020). Tal perspectiva, 
cabe apontar, está baseada nos processos de produção do conhecimento e envolve debates sobre o desenvolvimento do pensamento das ciências naturais. Parte dessa discussão é fruto da dimensão macrossocial (econômica) que conduz à dimensão das relações estabelecidas no processo do desenvolvimento desse conhecimento e relacionase com as interações entre campo político e científico. Tal representação confere aos cientistas tipos de capitais distintos que evocam tanto a dimensão do investimento no reconhecimento intelectual no campo (capital científico puro), quanto a dimensão das políticas institucionais (capital científico político) (Bourdieu, 2004). Quando se observa o capital científico puro, tal conhecimento, pela sua dimensão de difícil acesso, torna esse campo quase impenetrável para aqueles que não fazem parte desse espaço social, assim como dificulta em demasia que outros atores sociais possam inserir-se nesse meio sob o ponto de vista do desenvolvimento do conhecimento científico. Portanto, são poucos os agentes sociais que podem atuar nesse campo dando opiniões ou indicando caminhos de como a ciência deve desenvolver-se, ou seja, reconhecendo-a como um campo autônomo (Bourdieu, 2001).

Essa autonomia do campo (Bourdieu, 2004) configura-se como uma característica do espaço social da ciência, constituída pela sua historicidade, atribuindo um tipo de artefato social que garante sua legitimidade e sua salvaguarda diante dos distintos interesses políticos e econômicos que perpassam o trabalho dos cientistas e as demandas da sociedade (Bourdieu, 2003).

Mas, questiona-se, se podemos dizer que as ciências da natureza são saberes dito superiores na hierarquia do pensamento acadêmico e da sociedade de modo geral, isto pois o acesso à informação e a atual necessidade de diálogo entre universidade e sociedade não promove uma maior e melhor aproximação entre ciência e público geral. Enquanto as ciências produzidas pelos cientistas participantes de um jogo social que envolve diferentes disputas pela manutenção ou mudanças nas posições e relações de poder, a seleção dos conhecimentos curriculares do ensino de ciências, ainda que em outro espaço social, também configura como um saber próprio, comprometido com o espaço escolar, que perpassa suas lutas e interesses específicos.

Para tentar compreender tal reflexão, busca-se mobilizar a ideia de "arbitrário cultural" (Bourdieu \& Wacquant, 1992) como instrumento teórico que possa dar suporte para a reflexão sobre a relação entre conhecimentos das ciências naturais e o ensino. Ao aproximar-se da ideia de cultura como concepção antropológica, o autor não busca objetivamente definir superioridade às diferentes formas de representar o mundo (Bourdieu, 2011), ou seja, "os valores que orientariam cada grupo social em suas atitudes e comportamentos seriam, por definição, arbitrários, não estariam fundamentados em nenhuma razão objetiva, universal'. (Nogueira \& Nogueira, 2002, p. 28). Assim, o "arbitrário cultural", que aqui pode-se aproximar do ensino de ciências, não teria qualquer tipo de lógica ou justificativa que o levasse a um tipo de linguagem que possuiria mais legitimidade do que outra linguagem a ser ensinada ${ }^{5}$. Uma possível

5 Certa cautela é necessária nesse debate, pois o conhecimento científico é um saber instituído no campo pela racionalidade de seu pensamento, portanto, sua relevância passa pelo crivo dos cientistas. No caso do "arbitrário cultural”, o que se discute é como os modos como a ciência é apresentada podem levar a um tipo de privilégio cultural que alguns estudantes não possuem, como sua linguagem, por exemplo. 
defesa está no entendimento de que as ciências da natureza como saber escolar tem raiz em bens culturais comuns (Forquin, 1993) produzidos pela humanidade, sendo perpassados pela sua relevância como construção histórica e pautada na racionalidade. Contudo, como aponta Bourdieu e Passeron (2014) "todo ensino, e mais particularmente o ensino de cultura (mesmo científica), pressupõe implicitamente um corpo de saberes, de saber-fazer e sobretudo de saber-dizer, que constitui o patrimônio das classes cultas" (Bourdieu \& Passeron, 2014, p. 39).

Diante de tal debate, a pergunta que se coloca é se a transposição do conhecimento científico como bem simbólico no campo científico, ao se reelaborar enquanto um arbitrário cultural no espaço escolar, não poderia ser compreendido como um conhecimento com práticas e saberes que provêm de mesma estrutura epistemológica, mas com natureza social distinta. Tal questionamento visa compreender se a ideia de bem simbólico com valor dentro do campo social da ciência pode ser, também, um bem simbólico com valor social fora desse campo.

Essa reflexão leva-nos a defender que a aquisição do conhecimento científico no campo educacional proporcionaria papel tão relevante para a justiça social quanto deter esse bem simbólico para a desigualdade científico-tecnológica proposta por Tilly (2006). Partindo desse pressuposto, entende-se que Tilly (2006), ao mobilizar em seu trabalho o tema sobre a desigualdade científico-tecnológica, tem como instrumento reflexivo importante o entendimento do saber como aquele associado ao conhecimento do cientista. Para esse autor, a definição do que se entende atualmente por distinções em um mundo cada vez mais tecnológico e virtual está associado ao poder simbólico atrelado ao conhecimento das ciências. A ciência e a tecnologia - e seu desenvolvimento - se mostram importantes para definir o que seria uma nação poderosa politicamente, desenvolvida ou com potencial para tal (Tilly, 2006). Exemplos como o enriquecimento de urânio colocam à mesa termos significativos para decisões políticas, assim como o papel que o saber científico e tecnológico possui na construção de alianças e do respeito mútuo entre países dominantes nas políticas econômicas (Neves, 2015).

Como apontava Tilly (2006), os saberes da ciência e da tecnologia tornaram-se hoje instrumentos políticos significativos para definir as desigualdades, ao passo que no ambiente escolar, mobilizando uma leitura bourdieusiana, sua quase ausência pode evocar no aumento das distinções que se perpetuam ao longo da vida dos alunos, sendo destinado a cada sujeito um futuro reservado à sua classe social e cultural. Assim, a desigualdade científico-tecnológica, ainda que para Tilly (2006) esteja no âmbito das decisões geopolíticas e consequente perspectivas macrossociais, pode ser pensada no espaço das práticas microssociais quando se observa o papel das ciências naturais no contexto escolar como arbitrário cultural, conforme apontavam Bourdieu e Passeron (2013).

Um exemplo sobre tais diferenças ocorre na linguagem científica que é comunicada na escola através dos termos técnicos e que pode ser entendida como cerne da violência simbólica (Bourdieu, 1994). Isto pois a linguagem está representada na forma como o 
discurso é proferido, visto que seu viés acadêmico associado à fala da elite é a barreira estipulada pela dominação para a compreensão da ciência e não necessariamente os vocabulários técnicos (Archer et al., 2015).

Nesse sentido, o capital cultural (das elites) já está instituído nos modos de ser dos alunos (habitus) e institucionalizado no capital escolar das classes privilegiadas (Claussen \& Osborne, 2012). Já no campo científico, a linguagem é fator básico de entrada no campo, isto é, um candidato na área ao ignorar, por exemplo, elementos matemáticos ou termos técnicos, muito dificilmente terá espaço de atuação como cientista no campo da ciência (Gurgel \& Watanabe, 2020). Em suma, o espaço educativo como esse ambiente regulador da distribuição dos capitais culturais, pode ter encontrado no século XXI, no conhecimento das ciências naturais, o capital cultural e simbólico que precisa ser dosado no âmbito das frações de classes do qual ele deve ser ensinado e aprendido (Silva \& Wright, 2008).

As crises biográficas existentes na temática educacional levantam reflexões sobre como alunos fazem trajetórias distintas daquelas esperadas devido às suas origens sociais e, ainda que não sejam a maioria, são fontes importantes de análise. Contudo, cabe pensar que caminhos devem ser tomados para que as trajetórias distintas se tornem trajetórias rotineiras, o que leva o presente trabalho a iniciar alguns questionamentos sobre elementos macrossociais que buscam compreender a massa de alunos fora do ensino superior e aqueles que a adentram e, atuando às margens de uma educação pública, destinam seus esforços ao sistema universitário privado, por vezes, com menor prestígio social e acadêmico. Novamente, questiona-se o papel do conhecimento científico como instrumento político no contributo às desigualdades e justiça sociais e educacionais.

\section{Metodologia de Pesquisa}

As ciências sociais adotam a estatística como instrumento não só de diagnóstico, mas também de constatação de diversos aspectos da realidade, possibilitando as delimitações e análises dos espaços sociais. A busca por uma metodologia que possa incorporar a pesquisa crítica, no âmbito dos dados estatísticos, tem indicado uma tensão no campo da pesquisa educacional. Visto sob as limitações de tais métodos matemáticos, tem-se apontado em que medida trabalhar unicamente com dados quantitativos pode trazer visões capazes de compreender problemas complexos como os da educação (Ferrare, 2011).

Dentre os diferentes espectros da natureza de tais críticas, associadas aos modos (a)críticos do pensamento, cabe dar ênfase ao problema da causalidade. Para Ferrare (2011) quando estatísticos buscam compreender um atributo fixo a partir de diferentes associações com outros atributos fixos, acabam por promover relações diretas, enquanto, para os educadores críticos, tais relações são mais complexas, associadas à atores e objetos em processos inconstantes no tempo histórico. 
Explicar os fenômenos sociais é assim entendido como um processo de compreensão do contexto social (relações) nos quais os atores estejam inseridos. A maneira pela qual os pesquisadores causais/experimentais da educação lidam com a ideia de contexto é decididamente diferente dos pesquisadores críticos da educação. Os primeiros interessam-se pelo contexto na medida em que este os prepara para acrescentar precisão à sua explicação dos atributos fixos (Ferrare, 2011, pp. 513-514).

A própria escolha dos microdados de uma avaliação em larga escala traz desafios e reflexões sobre o problema levantado nesse artigo. Se a crítica ao contexto neoliberal na educação tem criado distorções sobre o sentido da escola, compreende-se que tais provas são tentativas de transformar a aprendizagem em um indicador quantitativo sem compromisso com o efetivo direito à educação dos jovens brasileiros (Libâneo, 2012). Portanto, seria prudente assumir que os microdados podem conduzir pesquisadores a interpretações equivocadas da qualidade educacional e encontram, em seu âmago, um viés acrítico da "educação para a reestruturação capitalista” (Libâneo, 2012, p. 20).

Para evitar tal armadilha, compreende-se que o fator determinante para entender o papel da estatística nesta pesquisa é que, alguns pesquisadores trabalham com a desigualdade na educação como uma variação de desempenho, reduzindo interpretação a localização do sujeito na distribuição de uma avaliação padronizada como o ENEM. Nessa pesquisa a estatística possui papel diferente pois indica, em termos dos estudos bourdieusianos, se o questionamento produzido na hipótese conduz a um problema verdadeiro $^{6}$ ou mais próximo do verdadeiro. Assim, pretende-se compreender se a ideia de que o conhecimento científico possui papel significativo ou inócuo para a desigualdade social é um questionamento plausível de ser trabalhado ou apenas uma visão acadêmica instituída pelo conjunto de problemas teóricos levantados ao longo da trajetória dos pesquisadores. Compreende-se que tal perspectiva pode evitar uma "redução teórica (que) ignora completamente as formas de desigualdade curricular (...), linguística (...), de capital cultural" que podem estar associadas aos dados trabalhados (Ferrare, 2011, p. 515).

Diante desse desafio, foram utilizados os dados fornecidos pelo Instituto Nacional de Estudos e Pesquisas Educacionais Anísio Teixeira - o INEP. O Instituto divulga, anualmente, os microdados a respeito do ENEM, sendo que os mesmos constituem o menor nível de agregação de dados recolhidos pelas pesquisas, avaliações e exames realizados. São dados de acesso livre e podem ser obtidos on-line ao acessar a plataforma digital $^{7}$. A análise apresentada refere-se aos microdados ${ }^{8}$ da edição de 2017 do ENEM.

Com os resultados obtidos, foi mobilizada uma análise baseada nos pressupostos da perspectiva da desigualdade científico-tecnológica como fonte de interpretação. Para a realização do estudo empírico, utilizou-se como critério de exclusão alunos que

6 Verdade na teoria de Pierre Bourdieu remete a proximidade com o sentido do real, com a dimensão social refletida nas práticas dos agentes sociais

7 http://inep.gov.br/web/guest/enem.

8 Os microdados da edição de 2017 podem ser encontrados em: http://inep.gov.br/microdados. 
participaram da prova de Ciências da Natureza e suas Tecnologias, mas não participaram do segundo dia de prova, ou seja, estiveram presentes em um dia, mas não em outro. Também, foram investigados somente aqueles que se declararam matriculados no terceiro ano do Ensino Médio e que o concluiriam em 2017 em uma escola brasileira $(\mathrm{n}=1.384 .929)^{9}$. Isto, pois, alunos que não estão matriculados em uma escola de educação básica, já concluíram ou irão concluir (treineiros) mas fizeram a avaliação - e estavam presentes nos dois dias de prova - são um número expressivo $(n=3.041 .167) \mathrm{e}$ precisaram ser retirados dos dados da análise para fins de perfil do corpus de pesquisa ${ }^{10}$. Todos os dados foram tratados com o software estatístico Alteryx Designer 2019.4.

As tabelas de desempenho estão separadas de acordo com a área do conhecimento e organizadas de acordo com o número de participantes por faixa de proficiência. Nossos esforços ficaram concentrados em organizar e sistematizar os resultados para que ficassem legíveis aos leitores. Nesse sentido, para cada área do conhecimento, representou-se os resultados em tabelas e gráficos de dispersão.

Concomitantemente, deu-se a investigação voltada a relacionar informações de infraestrutura escolar com os microdados do ENEM. Tal perspectiva foi possível pela manipulação e intersecção com os microdados do Censo Escolar de 2017, também disponibilizado pelo INEP ${ }^{11}$, com os microdados do ENEM 2017, a partir do código da escola dos candidatos. Desta forma, obteve-se os dados relacionados com a existência (ou não) de laboratórios didáticos de ciências nas escolas, cruzando-os com o desempenho dos candidatos. Tais dados se mostram mais uma perspectiva de análise de modo a contribuir na promoção de reflexões críticas e sociológicas, as quais são incorporadas neste estudo.

\section{Resultados e Discussões}

Antes de iniciarmos a análise e discussão dos dados, é importante salientar que em um panorama dos resultados (com dados totais) pode-se perceber que $1 \%$ dos estudantes possuem desempenho nos extremos do que seria uma curva gaussiana com notas muito baixas ou altas. Reconhece-se que tal distribuição está associada com o funcionamento do ENEM, uma vez que a prova adota o modelo de Teoria de Resposta ao Item (TRI) e não a Teoria Clássica dos Testes (TCT). Enquanto a TCT expressa os valores brutos ou padronizados, o TRI propõe modelos que analisam características de análise indireta (Ferreira, 2018). Isto implica que a nota do ENEM não é calculada somente de acordo com o número de acerto das questões, mas também considera a coerência das respostas, isto é, as questões do ENEM são classificadas em níveis de dificuldade de acordo com a proporção de sujeitos que acertam mais ou menos determinadas questões - quanto

9 Candidatos presentes nos dois dias de provas e que declararam que estavam cursando o Ensino Médio e o concluiria em 2017 eram 1.385.588. No entanto, 653 eram de escola estrangeira e 6 não havia informação sobre o tipo de gestão escolar. Resultando assim, numa população apta para análise de 1.384.929.

10 Candidatos excluídos da análise, mesmo estando presente nos dois dias de prova, que se autodeclararam: (1) Concluiu o EM ( $=2.529 .430)$; (2) Cursou o EM e não o conclui em 2017 (treineiros) ( $\mathrm{n}=481.766)$ e (3) Não concluiu ou não cursa o EM $(\mathrm{n}=29.971)$, totalizando 3.041.167.

11 O Censo Escolar de 2017, disponibilizado pelo INEP, pode ser acessado em: http://inep.gov.br/microdados. 
mais acertos possui dada questão, mais ela se enquadra como fácil, enquanto questões com baixa taxa de acertos são consideradas mais difíceis. A nota final do sujeito levará em conta não só as questões que ele acertou, como quais errou e qual o nível de dificuldade aquela questão teve naquele grupo amostral. Portanto, essa nota é calculada levando em consideração a quantidade de acertos e a coerência das respostas do participante.

Essa consideração é relevante, pois os dados apresentados aqui são fruto de um desempenho dos alunos ante o desempenho geral, comparativamente, dos outros candidatos. Ou seja, concebe-se que tão poucos estudantes obterem notas acima de 800 pontos e abaixo de 300 pontos, não está unicamente relacionado aos acertos e erros, visto que podem existir alunos que acertaram quase a totalidade das questões e, ainda, não alcançaram valores próximos aos mil pontos, e alunos que erraram quase a totalidade das questões não terem valores próximos a zero pontos.

Para a análise dos microdados, optou-se por tratar os resultados dos alunos das escolas públicas (estadual, federal ou municipal) e privadas, no escore de estudantes com faixa de "acertos" acima de 600 pontos em Ciências da Natureza. Conforme discutido anteriormente, o bem simbólico "conhecimento científico" (Bourdieu, 2004) tem se mostrado, segundo Tilly (2006), como um saber determinante para a desigualdade social. Assim, é importante compreender em que medida alunos que possuem alto desempenho nessa área do conhecimento, podem estar representados conforme sua formação na escola de origem. Sendo a educação um dos fatores mais marcantes da desigualdade social no país, pode-se reconhecer que o acesso ao saber da ciência mostrar-se-ia uma dimensão (dentre muitas) dessa distribuição desigual de capital cultural (Peregrino, 2010; Silva \& Wright, 2008).

Desse modo, para analisar a faixa de acerto em Ciências da Natureza acima de 600 pontos, focou-se em detalhar a relação de desempenho dos alunos dessas escolas com o intuito de, posteriormente, tratar os microdados para comparar seus resultados. Cabe apontar que em alguns momentos as escolas públicas estão englobadas em estaduais, municipais e federais, mas adiantando que não influenciam os dados de modo significativo pelo volume de estudantes da escola estadual. Contudo, à frente, esses dados serão apresentados separadamente para fins de detalhamento do debate.

Os resultados mostrados na Figura 1 são apresentados em números absolutos e percentuais, em relação à distribuição das faixas de notas em Ciências da Natureza. Vemos nos dados, como já apontado por Silva e Ney (2011), que ao passo que o grosso dos alunos das escolas públicas vão sendo deixados para trás em termos de representatividade, os alunos das escolas privadas iniciam sua caminhada para o "sucesso escolar" com indicativos marcados das distribuições de desempenho escolar.

A representação percentual foi realizada, pois o número de alunos das escolas públicas é, em números absolutos, muito maior que os alunos das escolas privadas, impossibilitando a representação de um gráfico comparativo (Figura 1). 
Figura 1. Distribuição de candidatos em frequência de acertos em ciências da natureza em números absolutos e percentuais
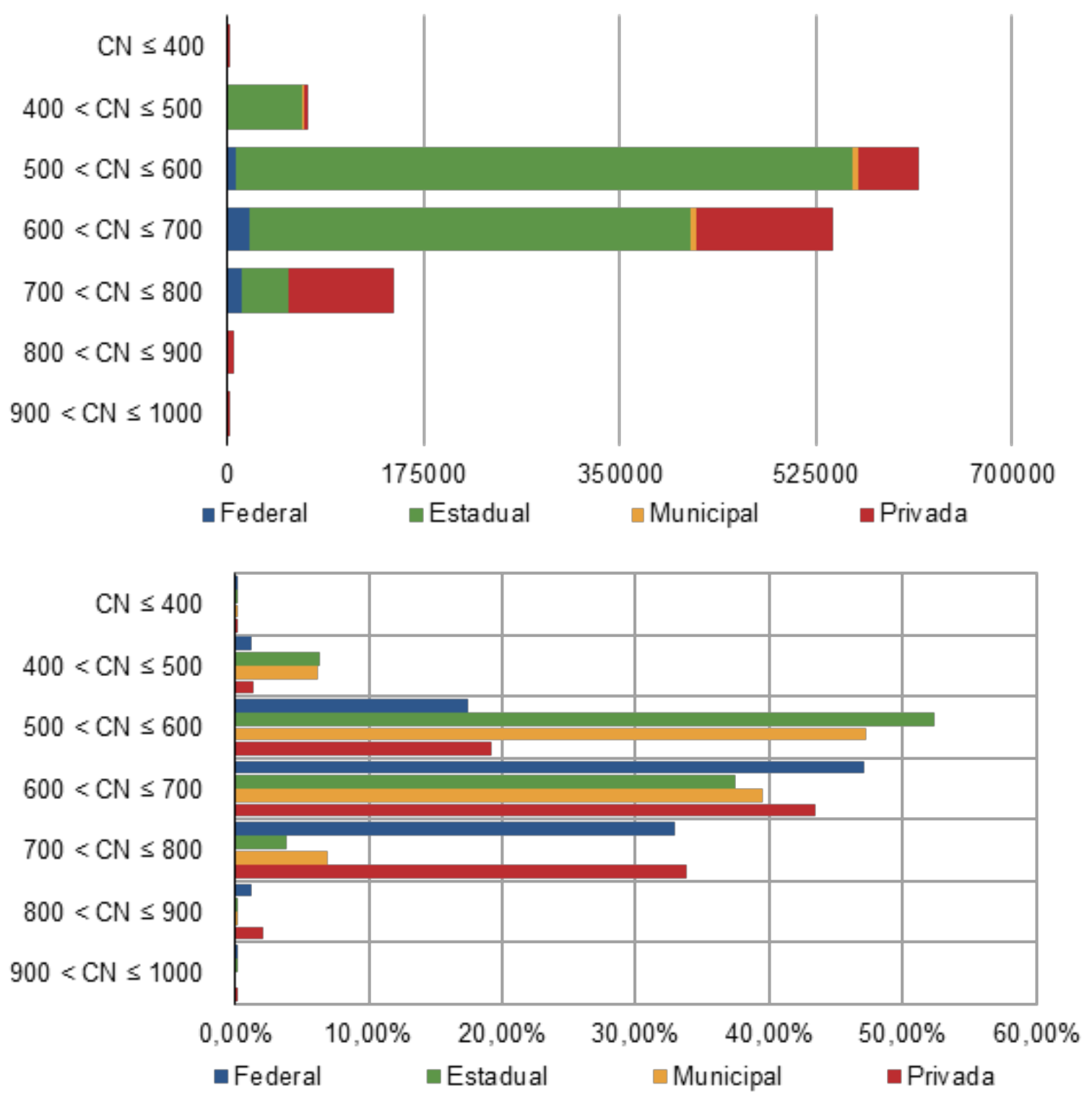

Fonte: elaboração própria.

Ao observarmos as distribuições percentuais de alunos por faixa, conforme representado pela Figura 1, percebe-se que a distância dos alunos das escolas estaduais e privadas cai drasticamente na faixa 600-700, e inverte-se em representação total na faixa de acertos em 600 pontos. Nota-se que desempenho parecido tem estudantes das escolas federais, contudo, são em números absolutos bem menores que os das escolas privadas, o que dialoga com trabalhos próximos aos aqui apresentados (Nascimento et al., 2019).

Se durante a distribuição de notas sempre há mais alunos das escolas estaduais que privadas sendo representados até a faixa 500-600 pontos, o que se pode considerar normal, visto que há numericamente mais alunos nas escolas públicas que privadas, 
quando as notas em ciências da natureza adentram a faixa dos 600-700 pontos, observase que essa distribuição se inverte. Em particular, podemos perceber uma distribuição desigual quando observamos os alunos que conseguem pontuar na faixa superior de 900 pontos em diante. Chama a atenção que, nesse caso, os representantes das escolas privadas são 55 alunos, enquanto, na escola estadual tem-se 1 representante que consegue chegar ao ápice da nota nas provas de Ciências da Natureza no ENEM do ano de 2017.

Essa discrepância torna-se mais explícita quando se leva em conta que o total de alunos, em números absolutos, na prova de Ciências da Natureza é comparado por dependência administrativa: na rede estadual é de 1.050 .516 , enquanto na rede privada conta-se com 278.747 alunos. Sendo assim, ao olharmos proporcionalmente aos totais do universo de cada grupo, aproximadamente, tem-se que $79,34 \%$ de todos os alunos $(n=221.182)$ da rede privada possuem resultados na faixa de 600 pontos em diante enquanto $41,32 \%$ de todos os alunos da rede estadual $(n=434.177)$ pontuaram na mesma faixa. Tais resultados, ainda de modo geral, indicam que há discrepâncias entre alunos das escolas públicas e privadas no que se refere ao conhecimento das Ciências da Natureza. Essa dimensão global dos dados do ENEM não pode ser reconhecida como fator inicialmente marcante para compreender o impacto das ciências naturais na desigualdade educacional e social (Kleinke, 2017). Assim, pretende-se olhar de modo mais detalhado a distribuição das notas das escolas públicas e privadas no que tange ao conhecimento científico em termos comparativos às outras áreas para subsidiar o debate proposto.

Se para Tilly (2006) a ciência e tecnologia se mostram como um aparato de poder político que influencia diferentes esferas da sociedade, deixando, no século XXI, um conjunto de atores sociais na periferia do debate sobre essas decisões políticas, talvez haja indicativos de como tal conhecimento pode impactar o desempenho dos alunos, também, para o ingresso no ensino superior (ou se não possui qualquer tipo de relação comparada às outras áreas do ENEM) (Helene, 2013).

Diante do exposto, optou-se em reconhecer como são distribuídas as notas desses jovens com bom desempenho nessa área do saber em comparação aos outros conhecimentos presentes na avaliação. Isto, pois compreende-se a importância em analisar em que medida os alunos possuem vínculos associados ao capital cultural e à sua relação com as ciências da natureza (Claussen \& Osborne, 2012). Essa relação, entendese, influenciada pelas outras áreas do conhecimento, que pode apresentar indicativos de seu papel na formação educacional dos alunos diante do desempenho global na prova (Peugny, 2014; Pires, 2015; Silva et al., 2011).

Para tentar iniciar essa análise, o gráfico da Figura 2 ilustra o comportamento das médias gerais de cada eixo do conhecimento e do tipo de escola de origem, agrupando em intervalos de notas em Ciências da Natureza dos candidatos. 
Figura 2. Médias de notas em agrupamentos por intervalos de notas em Ciências da Natureza

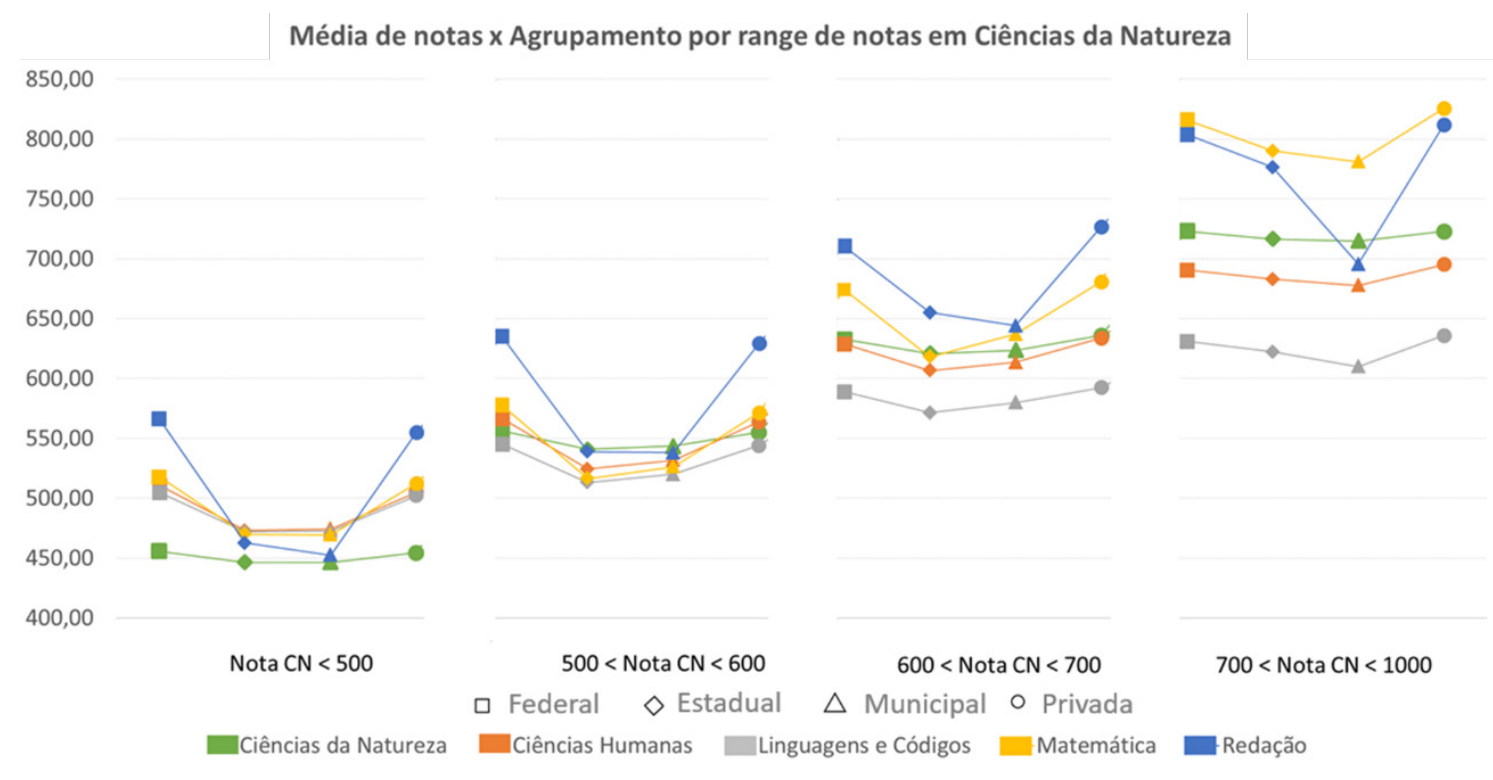

Fonte: elaboração própria.

Para a leitura do gráfico da Figura 2, pode-se observar que as faixas abaixo de 500 e acima de 700 foram agrupadas e apresentadas em um único intervalo para facilitar a leitura do gráfico. O gráfico apresentado tem o intuito de promover a comparação de desempenho entre escolas (em termos de suas notas para cada área). Assim, pode-se observar que em verde estão todas as notas referentes às Ciências da Natureza e, para o símbolo quadrado, os representantes das escolas federais, seguido do símbolo losango para o grupo estadual e assim por diante. Tal lógica se repete para cada intervalo de notas obtidas.

Depreende-se que os candidatos que obtiveram pontuação menor que $500 \mathrm{em}$ Ciências da Natureza, também foram os que apresentaram as menores médias de Ciências da Natureza frente as outras áreas do conhecimento, o que não ocorre em todas as outras faixas de pontos, independentemente do tipo de escola. Esse fator parece apresentar um papel importante e que merece estudos mais detalhados. Contudo, cabe indicar que o baixo desempenho desses estudantes das Ciências da Natureza podem dar indícios da questão apontada por Tilly (2006) sobre como o conhecimento científico-tecnológico possui uma faceta que precisa ser mais bem explicada como, no caso estudado, reflete o pior desempenho nessa área se comparada à todas as outras para os alunos que possuem notas abaixo de 500. Nesse caso, como apontam Claussen e Osborne (2012) e Archer et al. (2015), as ciências e seu papel social, atrelados ao espaço escolar, precisam ser debatidos diante das diferentes desigualdades que geram na formação dos alunos.

Em direção às maiores pontuações, observa-se a preponderância das médias de Redação e Matemática. Já as relacionadas às Linguagens e às Ciências Humanas, permanecem como as de menores médias, enquanto que às de Ciências da Natureza há uma ascensão, equiparando-as no intervalo de "500 < Nota $\mathrm{CN}<600$ ” e se sobrepondo 
em "700 < Nota $\mathrm{CN}<1000$ ", independente da origem escolar do candidato. Chamase a atenção das escolas da rede federal (Institutos Federais de Educação, Ciência e Tecnologia) que acompanham o desempenho das escolas privadas. Tal debate, como já apontado por Nascimento (2019), indica diferentes fatores, como a carreira dos docentes do magistério federal e as provas de seleção dessas instituições que constituem um gargalo social e cultural para os alunos dos institutos federais, resultado de uma "superseleção" desses alunos (Bourdieu, 1964). Observa-se, portanto, que as notas de Ciências da Natureza ganham, em termos comparativos gerais às outras áreas, papel proeminente para alunos que possuem acesso a esse saber em notas acima de 600 pontos em oposição às Ciências Humanas e Linguagem. Tal resultado pode ser compreendido como uma interessante inversão e, consequente impacto desse conhecimento, ao passo que o estudante parece obter melhor sucesso na avaliação do ENEM quando as Ciências da Natureza se tornam mais relevantes comparativamente às outras duas áreas. Tal aspecto mostra, ainda que inicialmente, que há certa aproximação com o debate de que as ciências naturais se revelam como um possível conhecimento para a justiça social, ao se perceber que da faixa 700 em diante o aluno da escola estadual possui desempenho significativo comparado aos outros intervalos (Libâneo, 2012; Krawczyk \& Silva, 2017).

No entanto, os resultados acima pouco apresentam sobre como as ciências naturais podem impactar no desempenho dos alunos das escolas públicas e privadas. Para buscar trazer uma análise mais detalhada, compreende-se ser necessário observar o perfil dos acertos e erros das outras áreas de conhecimento e como estão se comportando em relação às Ciências da Natureza. Para tanto, podemos observar que, conforme já encontrado em outros trabalhos (Nascimento, 2019), o perfil das escolas públicas federais como os Institutos de Educação, Ciência e Tecnologia (IFs) e das privadas possuem semelhanças (Kleinke, 2017; Nascimento et al., 2019). É provável que os alunos da rede federal se assemelhem aos da rede privada por serem frutos de um processo de superseleção (Nogueira \& Nogueira, 2002), isto é, esses sujeitos, ao longo de sua trajetória, teriam sobrevivido a diversas seleções com base, principalmente, em seu capital cultural (Bourdieu \& Passeron, 2013; Peugny, 2014; Setton, 2011; Silva et al., 2011).

Para buscar algumas interpretações para tais demandas, foram elaboradas análises compostas por dois gráficos de dispersão ${ }^{12}$; um gráfico de distribuição normal; e uma tabela com a distribuição em porcentagem. Para esta análise, como já apontado anteriormente, foram considerados apenas candidatos que obtiveram nota maior ou igual a 600 pontos em Ciências da Natureza.

No que tange aos gráficos de dispersão, localizados na parte superior das figuras 3, 4, 5 e 6, tem-se no eixo horizontal a pontuação em Ciências da Natureza e no eixo vertical a comparação de notas do próprio candidato de uma determinada área do conhecimento com a de Ciências da Natureza. Apenas a título de exemplificação: um

12 Esses dois gráficos precisam ser analisados de maneira integrada, como um único resultado. Foi necessária a separação de dois gráficos devida a dificuldade de observação dos dados, visto que há um número expressivo de alunos das escolas privadas que dificultaram a visualização geral da distribuição. 
candidato que obteve 600 pontos em Ciências da Natureza e 700 em Ciências Humanas, ao compararmos suas notas de Ciências Humanas com a da Ciências da Natureza teríamos $1,1666(700 / 600=1,1666)$, isto é, o candidato obteve pontuação cerca de $16,66 \%$ maior em sua nota de Ciências Humanas se comparada a sua nota em Ciências da Natureza. Sendo assim, no gráfico, este candidato seria registrado como um ponto de interseção do eixo horizontal $(600)$ com o eixo vertical em $(1,1666)$. De forma sumária, para o eixo vertical, podemos interpretar que candidatos que estão acima do valor 1, obtiveram nota de Ciências da Natureza inferior se comparada ao outro eixo do conhecimento; se igual a 1, o candidato tirou a mesma nota em Ciências da Natureza e em outro eixo; se menor que 1, o candidato obteve maior nota em Ciências da Natureza do que a de outro eixo do conhecimento.

O gráfico de distribuição normal - na parte inferior das figuras 3, 4, 5 e 6 temos no eixo horizontal a comparação da pontuação de Ciências da Natureza com a de um determinado eixo do conhecimento (análogo ao eixo vertical do gráfico de dispersão), e no eixo vertical a densidade de probabilidade.

A tabela - localizada na parte central das figuras 3, 4, 5 e 6 - apresenta a distribuição (em porcentagem) dos candidatos a partir da comparação de pontuações de um determinado eixo de conhecimento e do de Ciências da Natureza, do próprio candidato. Para tal distribuição, temos três cenários: inferiores a um desvio padrão; -1 desvio padrão $\leq$ média geral $\leq+1$ desvio padrão; superiores a um desvio padrão. Vale ressaltar que, matematicamente, o intervalo compreendido entre "- 1 desvio padrão $\leq$ média geral $\leq+1$ desvio padrão” representaria uma concentração de cerca de $68,26 \%$ dos candidatos que estavam presentes nos dois dias de prova, eram do terceiro ano do Ensino Médio, e obtiveram pontuação igual ou maior que 600 em Ciências da Natureza. Sendo assim, objetiva-se com esta tabela apresentar como os candidatos estão distribuídos, a partir do tipo de escola de origem.

Conforme apresentado na Figura 3 observa-se, através de uma análise macrossocial, uma variação máxima de cerca de 50\% entre a pontuação de Ciências da Natureza e a da Matemática, isto é, chegando próximo dos 1.5 (candidato obteve pontuação em Matemática de quase $50 \%$ superior, se comparado à sua nota em Ciências da Natureza) e 0.5 (obteve nota de Ciências da Natureza de quase $50 \%$ maior se comparado à sua nota de Matemática). Em direção às crescentes pontuações em Ciências da Natureza, no entanto, há uma tendência de redução desta variação, e uma leve ascensão para quadrantes superiores à 1.0, indicando que os candidatos tiveram desempenho levemente melhor em Matemática do que em Ciências da Natureza. 
Figura 3. Relação Matemática x Ciências da Natureza
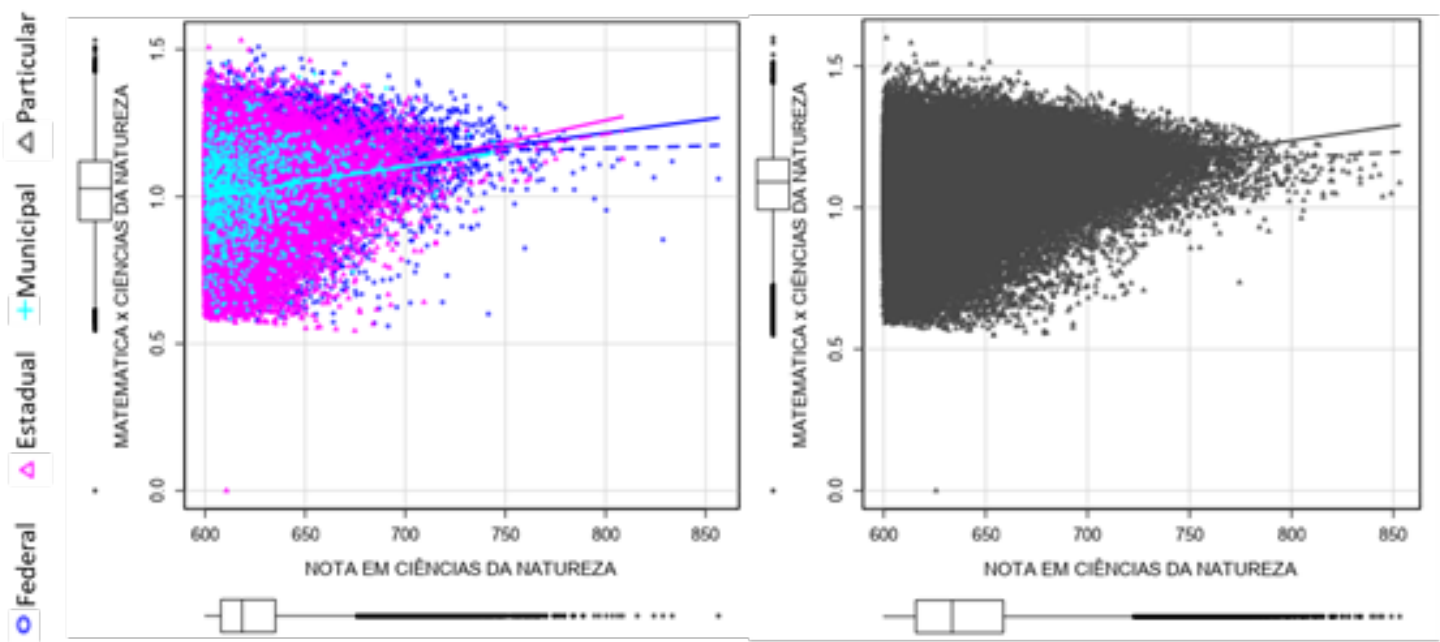

\begin{tabular}{ccc|ccc|c}
\multicolumn{7}{c}{ Matemática x Ciências da Natureza } \\
Total candidatos & $<\mathbf{0 , 9 0 6 9 0 3}$ & $\mathbf{0 , 9 0 6 9 0 3} \leq \mathbf{M T} \mathbf{x} \mathbf{C N} \leq \mathbf{1 , 1 9 8 3 5 5}$ & $>\mathbf{1 , 1 9 8 3 5 5}$ & Escola origem \\
\hline \hline 14312 & $13,81 \%$ & $68,61 \%$ & $17,57 \%$ & Federal \\
40410 & $26,51 \%$ & $66,39 \%$ & $7,10 \%$ & Estadual \\
977 & $19,65 \%$ & $71,65 \%$ & $8,70 \%$ & Municipal \\
100136 & $12,37 \%$ & $69,68 \%$ & $17,95 \%$ & Privada
\end{tabular}

Média: 1,052629

$\sigma: 0,145726$

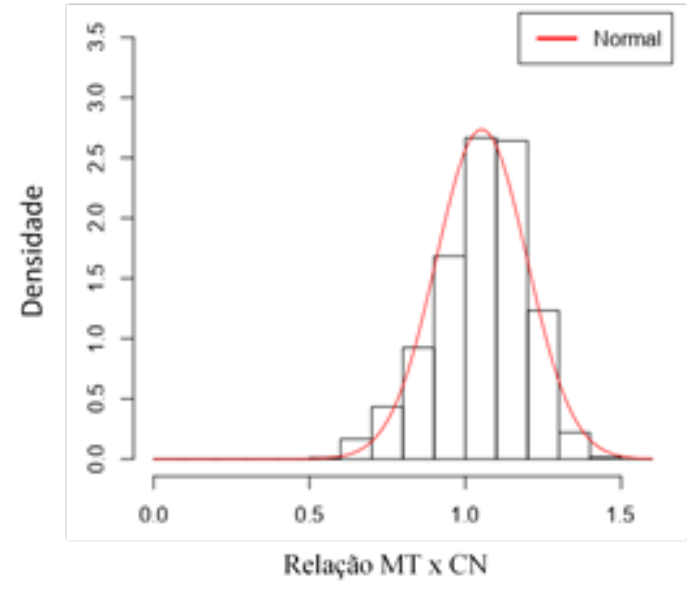

Fonte: elaboração própria.

Outra informação a ser destacada é que, quando analisamos estes candidatos com pontuação igual ou superior a 600 em Ciências da Natureza, os oriundos das redes Estaduais e Municipais superam - em porcentagem - os candidatos da Privada e Federal no intervalo " $<0.906903$ " (obtiveram a nota em Ciências da Natureza maior que a de Matemática, em pelo menos 10\%) e estão mais distribuídos neste, do que no de “> 1.198355". Portanto, ao analisarmos os extremos, os candidatos das redes Estadual e Municipal tendem a ir melhor em Ciências do que Matemática.

A Figura 4 apresenta a comparação de Ciências Humanas com Ciências da Natureza. Conforme tabela, mais uma vez, ao comparar os intervalos extremos em porcentagem, os candidatos na rede Estadual e Municipal se distribuem mais para o 
intervalo em que os candidatos obtiveram notas superiores em Ciências da Natureza do que em Humanas.

No que tange ao gráfico de dispersão da Figura 4, observa-se uma tendência descendente suave para os quadrantes abaixo do valor 1.0 conforme aumenta-se a nota em Ciências da Natureza. A média geral de 0.9899, com desvio padrão em 0,0710 nos orienta que a comparação das notas de Ciências Humanas e da Natureza não são tão dispersas quanto as de Matemática e Ciências da Natureza, as quais possuíam média geral em 1.05526 e desvio padrão 0.1457 .

Figura 4. Relação Ciências Humanas x Ciências da Natureza
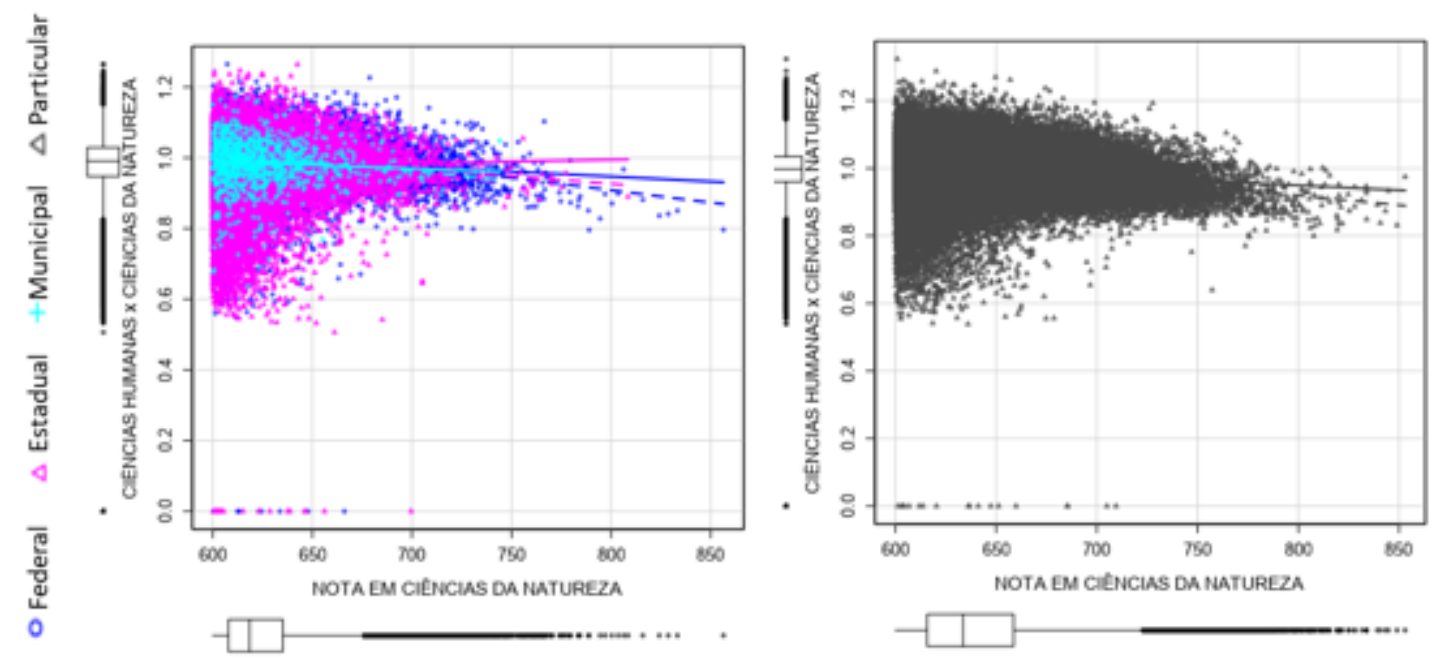

\begin{tabular}{c|c|c|cc}
\multicolumn{6}{c}{ Ciências Humanas x Ciências da Natureza } \\
Total candidatos & $<\mathbf{0 , 9 1 8 8 6 8}$ & $\mathbf{0 , 9 1 8 8 6 8} \leq \mathbf{C H}$ x CN $\leq \mathbf{1 , 0 6 0 9 9 4}$ & $>\mathbf{1 , 0 6 0 9 9 4}$ & Escola origem \\
\hline \hline 14312 & $10,61 \%$ & $76,10 \%$ & $13,29 \%$ & Federal \\
40410 & $16,47 \%$ & $73,64 \%$ & $9,90 \%$ & Estadual \\
977 & $12,49 \%$ & $77,89 \%$ & $9,62 \%$ & Municipal \\
100136 & $9,30 \%$ & $78,03 \%$ & $12,67 \%$ & Privada
\end{tabular}

Média: 0,989931

$\sigma: 0,071063$

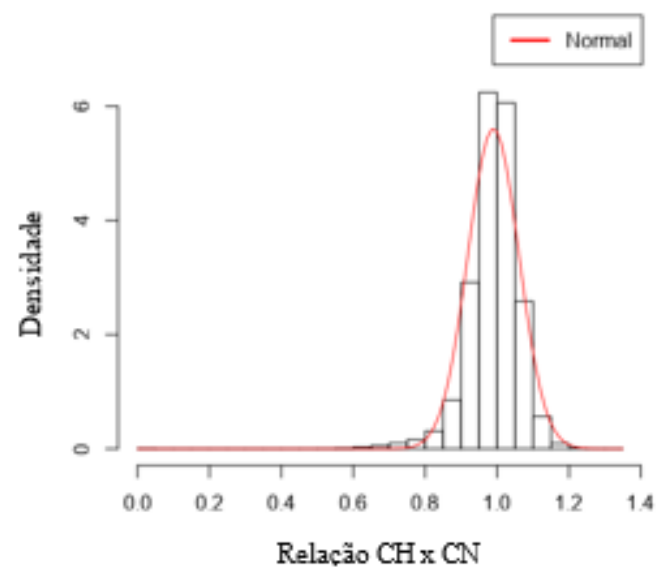

Fonte: elaboração própria.

Da Figura 5, que apresenta os gráficos de dispersão de Linguagens e Códigos e Ciências da Natureza, também é possível inferir, ainda com mais ênfase, a característica 
descendente para quadrantes abaixo de 1. Isto, portanto, significa que maior parte dos candidatos analisados de 2017 obtiveram uma nota maior em Ciências da Natureza se comparada às suas pontuações em Linguagens, tanto é que a média geral da comparação ficou em 0,9270 com $\sigma=0.0628$.

A tabela de distribuição em porcentagens sinaliza também que boa parte dos candidatos estão nos quadrantes inferiores a 1 , reforçando que a maioria dos candidatos teve sua nota em Ciências da Natureza maior do que em Linguagens e Códigos. Ademais, ao compararmos os extremos, mais uma vez os candidatos da rede Estadual estão mais concentrados (em porcentagem) no intervalo que indica ter obtido uma nota superior em Ciências da Natureza do que Linguagens. E isto não é diferente quando comparamos Redação e Ciências da Natureza.

Figura 5. Relação Linguagens e Códigos x Ciências da Natureza
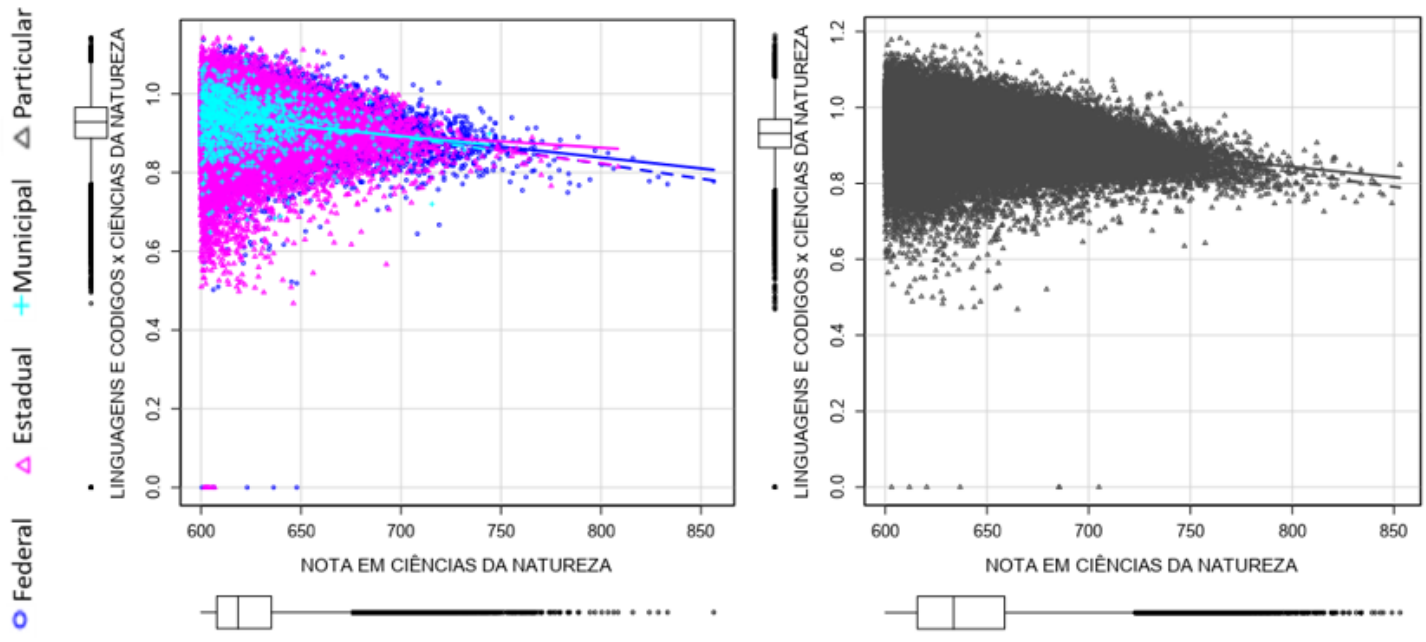

\begin{tabular}{c|c|c|c|c|}
\multicolumn{5}{c}{ Linguagens e Códigos $\mathbf{x}$ Ciências da Natureza } \\
Total candidatos & $<\mathbf{0 , 8 6 4 1 6}$ & $\mathbf{0 , 8 6 4 1 6} \leq \mathbf{L C} \times \mathbf{~ C N} \leq \mathbf{0 , 9 8 9 8 6 4}$ & $>\mathbf{0 , 9 8 9 8 6 4}$ & Escola origem \\
\hline \hline 14312 & $12,30 \%$ & $72,97 \%$ & $14,72 \%$ & Federal \\
40410 & $16,90 \%$ & $70,51 \%$ & $12,58 \%$ & Estadual \\
977 & $12,49 \%$ & $73,29 \%$ & $14,23 \%$ & Municipal \\
100136 & $12,50 \%$ & $72,97 \%$ & $14,53 \%$ & Privada
\end{tabular}

Média: 0,927012

$\sigma: 0,062852$

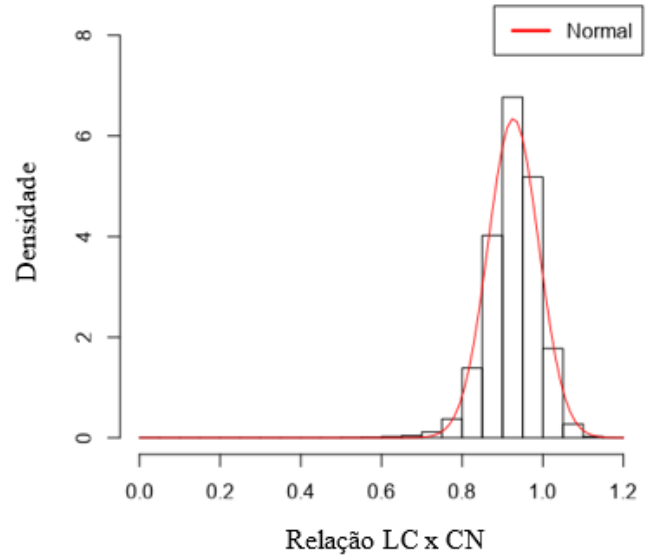

Fonte: elaboração própria. 
A Figura 6, também indica que há uma concentração maior de candidatos oriundos das escolas Estadual e Municipal em "< 0.910478", com 21,34\% e 22,52\%, respectivamente, enquanto a rede privada possui $10,10 \%$ do seu público neste intervalo e a Federal, 11,84\%. Por outro lado, do gráfico de dispersão, é possível inferir que há uma variação das notas de um mesmo candidato quando comparamos sua pontuação em Ciências da Natureza e Redação.

Conforme apontado nos dados pode-se apreender que a prova de Ciências da Natureza está se mostrando importante na formação dos alunos das escolas públicas no ENEM. Chama a atenção perceber em que medida tal distribuição afeta positivamente o desempenho final da nota dos alunos das escolas públicas se comparado ao desempenho dos estudantes das escolas privadas ou federais. O que esses resultados parecem indicar é que há uma massa significativa de alunos oriundos das escolas públicas estaduais que possuem desempenho em ciências da natureza que pode lhes dar suporte para concorrer aos cursos de alta seletividade.

Figura 6. Relação Redação x Ciências da Natureza

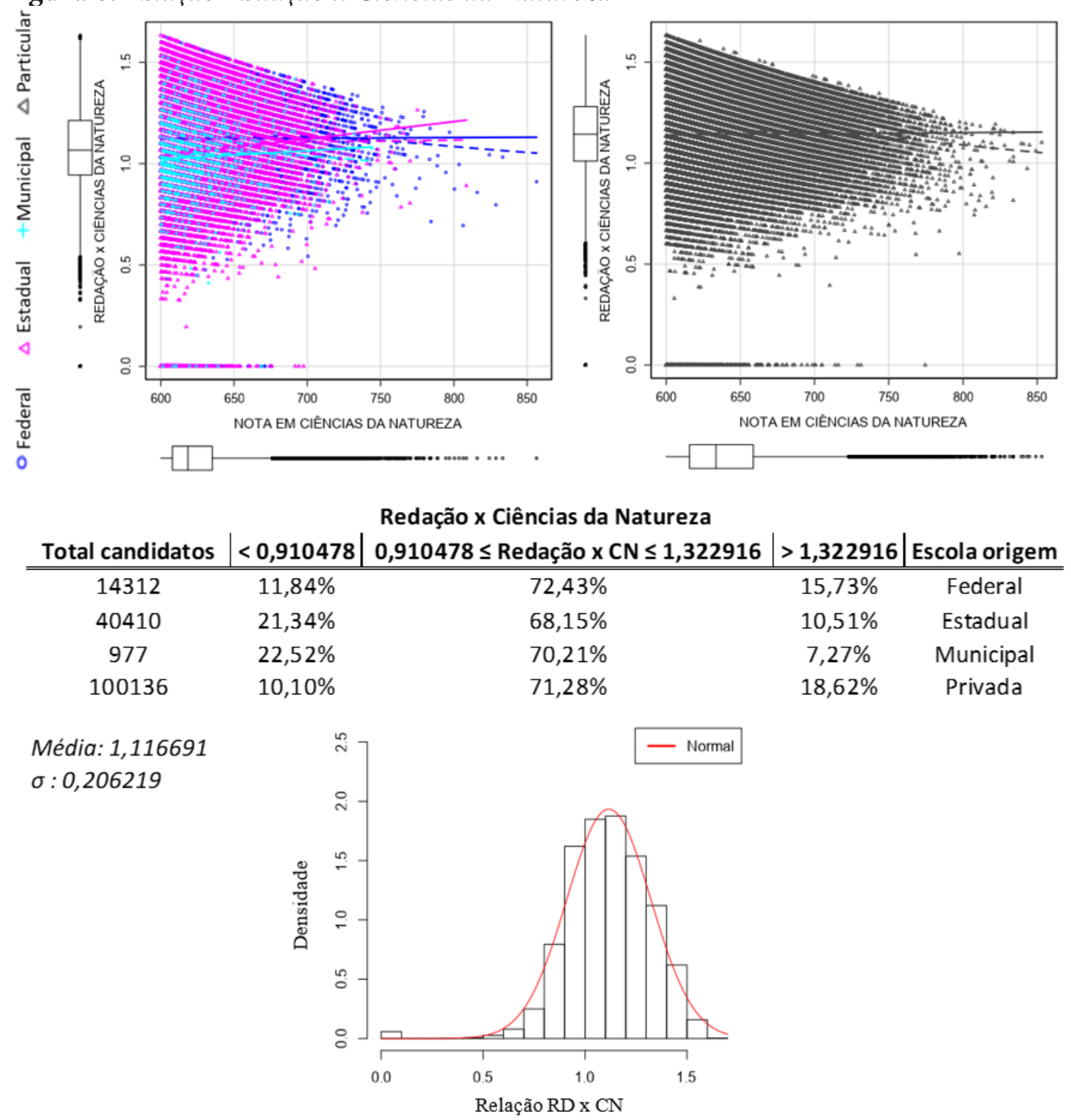

Fonte: elaboração própria. 
Sob o ponto de vista global, pode-se reconhecer que os níveis de acertos associados aos saberes das ciências naturais não são mantidos conforme a média global dos alunos das escolas públicas e privadas. Enquanto observa-se na análise geral as distribuições das notas dos alunos das escolas estaduais, pode-se perceber, de modo bastante marcante, a quantidade de alunos que não ultrapassam os 600 pontos, totalizando 616.339 dos 1.050 .516 alunos, isto é, cerca de 58,67\%. Ao estudar a distribuição das notas gerais em ciências naturais, o pico médio de acertos da curva gaussiana dos alunos das escolas estaduais, percebe-se que a concentração se dá entre 400 até 550 pontos, com média de, aproximadamente, 488 pontos. Enquanto que os candidatos da rede privada, no geral, possuem um pico médio entorno de 565 pontos em ciências naturais, e ao analisarmos o mesmo intervalo (de até 600 pontos), possuem uma representatividade de apenas 20,65\% (57.565 dos 278.747). Tais dados são preocupantes, mas indicam, como já vem sendo tratado por diferentes autores na área, o descompasso entre as escolas pública e privada no Brasil (Libâneo, 2012) e o papel do conhecimento científico no espaço escolar (Archer et al., 2015; Claussen \& Osborne, 2012).

Para buscar caminhos para reflexões, encontrou-se uma relação que demonstrou potencialidade para essa pesquisa. Para tanto, foi realizada uma associação dos microdados do ENEM 2017 com o Censo Escolar de 2017, ambos disponíveis no site do INEP $^{13}$. Essa análise foi feita a partir da disponibilidade do código da escola do candidato e procurou-se relacionar possíveis índices que dessem pistas em relação à infraestrutura e formação docente, dando alguns indícios acerca do desempenho dos estudantes na área de Ciências da Natureza. Novamente, ressalta-se que foram considerados os candidatos aptos a serem analisados aqueles que estavam presentes nos dois dias de prova do ENEM e que estavam no terceiro ano do Ensino Médio. Ademais, para esta análise, dos 1.384.929 estudantes iniciais, 1.383.478 possuíam um código de escola associado ao censo escolar ${ }^{14}$. Nesse sentido, dos 1.384 .929 estudantes, 763.387 deles possuíam laboratórios em suas respectivas escolas, 616.262 não possuíam laboratórios em suas respectivas escolas, 3.829 estudantes não apresentaram informações acerca da infraestrutura escolar apesar de terem escola associada ao censo, e 1.451 estudantes não apresentavam código de escola associada ao censo.

Desse modo, dos 763.387 estudantes cujas escolas tinham laboratórios de ciências, 37.689 eram estudantes de escolas Federais, 544.401 eram estudantes de escolas Estaduais, 4.732 eram estudantes de escolas Municipais e 176.565 eram estudantes de escolas Privadas.

Dos dados depreende-se, de forma geral, que conforme há uma elevação das notas em Ciências da Natureza, maior é a representatividade de candidatos que estudavam em uma escola que possuía laboratório de ciências e vice-versa ${ }^{15}$. Do público analisado,

13 Site INEP, com microdados ENEM 2017 e Censo Escolar 2017: http://inep.gov.br/microdados.

14 No que tange a existência ou não de laboratórios na escola, o Censo Escolar 2017 possuía três opções: sem laboratório, com laboratório ou "vazio", isto é, não foi declarado tal infra-estrutura e, portanto, não foi contabilizado nas porcentagens apresentadas neste estudo.

15 Observa-se que há uma diminuição percentual da presença de laboratórios para os casos acima de 700 pontos, contudo, conforme discutido anteriormente, com representação em números absolutos menores. 
observa-se com destaque a média dos candidatos oriundos da rede Federal, em que 90,64\% deles possuíam em sua escola um laboratório de ciências. Ainda que apresente uma leve diminuição nas taxas percentuais da presença de laboratórios nos institutos, compreende-se que essa diferença não se torna impactante ao longo de todas as faixas estudadas. Não obstante, os candidatos da escola privada, configuraram em $64,01 \%$, contudo, com crescente percentual conforme as notas aumentam. No entanto, o caso a ser analisado refere-se às instituições estaduais e municipais. Observa-se que a taxa percentual de laboratórios de ciências nessas instituições é crescente ao passo que os estudantes conseguem obter melhor desempenho até 700 pontos no ENEM. Ainda que percentualmente esses resultados são parecidos com os das escolas privadas em termos da taxa de aumento, o caso se mostra mais grave quando observa-se que na faixa abaixo de 500 pontos há, em número absoluto, valores significativos de estudantes que estão na rede estadual. Implica reconhecer que mais da metade ${ }^{16}$ das escolas representadas por $308.520{ }^{17}$ candidatos da rede estadual não possui um laboratório de ciências naturais ${ }^{18}$.

Ainda que neste artigo não objetivamos uma mera correlação que "uma melhor nota” em Ciências da Natureza provém da presença de um laboratório na escola do candidato, entendemos ser uma primeira oportunidade de reflexão a partir dos dados de 2017. Ademais, a existência de um laboratório em uma escola, não significa necessariamente que aquele candidato teve práticas naquele espaço, no entanto, os dados indicam uma possível estrutura da escola que forneça possibilidades e oportunidade de diferentes aprendizados e experimentações para os seus alunos (Peregrino, 2010; Libâneo, 2012).

Corroborando com essa discussão, o Censo Escolar de 2017, indicou que apenas 38,8\% das escolas públicas de Ensino Médio do país possuem laboratórios de ciências, aumentando para 57,2\% nas privadas e 83,4\% nos Institutos Federais (Ministério da Educação, 2019). Fato que se complexifica quanto à formação e condições de trabalho dos profissionais que atuam nessas áreas (Alves \& Pinto, 2011; Helene, 2013). Cabe lembrar que cerca de $42 \%$ dos professores de Física no Ensino Médio possuem formação na área enquanto, no caso da Química, têm-se 62\%, aproximadamente, desses profissionais atuando nas disciplinas específicas de sua formação.

Diante dos números, fica o debate sobre de que maneira a universidade pode ser um "espaço de possíveis" ${ }^{19}$ " (Bourdieu, 2011; Archer et al., 2015) para alunos de instituições públicas e, ainda, como a carreira científica pode ser um lugar possível de

16 Somente 49,85\% das escolas possuem laboratórios de ciências segundo dados do Censo Escolar 2017 e condições implicadas deste estudo.

17 Ressalta-se que são candidatos presentes nos dois dias de prova, estavam no último ano do Ensino Médio da rede estadual e obtiveram desempenho menor ou igual a 500 pontos em Ciências da Natureza e suas Tecnologias. Ademais, nesta condição, havia outros 876 candidatos provenientes de escolas estaduais, tais quais não declararam se possuem, ou não, um laboratório de ciências (condição "vazio").

18 Para interpretar esse dado é preciso levar em conta o corpus da análise e o número de escolas que estão representadas por mais de um estudante.

19 Termo usado pelo autor para definir o conjunto de disposições que mobilizam a gênese do mundo social e que indicam os investimentos sociais e culturais para futuro lucro no espaço social investido. Ver mais em "O senso prático" de Pierre Bourdieu (2011). 
ser adentrado quando menos da metade das instituições que formam esses estudantes possuem um espaço destinado às atividades experimentais. Ressaltamos a importância do espaço em questão ao compararmos as notas das escolas federais, visto que, como discutido anteriormente, são parecidas com o desempenho das instituições privadas, em média.

Esses resultados obtidos conforme análise dos dados do ENEM 2017 visam trazer algumas discussões sobre as dimensões do capital cultural à luz da teoria de Pierre Bourdieu e da desigualdade de Charles Tilly. Nesse sentido, são reconhecidos elementos associados aos capitais que dominam certos modos de conduzir as práticas culturais ou reconhecidas pelos meios formais que diferenciam as classes sociais. Maior representatividade dessa discussão é encontrada quando se reconhece que:

(...) a renda das pessoas depende fortemente da quantidade e da qualidade da educação formal que receberam; e, formando um círculo vicioso, a educação das crianças e dos jovens depende, também, fortemente, de sua renda familiar. A combinação desses dois fatores faz com que nossa política educacional seja um dos principais fatores de concentração de renda e da reprodução das desigualdades (Helene, 2013, p. 29).

Ao tratar o círculo vicioso da renda-educação-renda (Helene, 2013) pode-se reconhecer que famílias com baixo capital econômico conduzem suas relações com o mundo escolar de modo pragmático, investindo na formação de seus filhos conforme as dimensões cotidianas lhes indicam sucessos e fracassos (Bourdieu \& Passeron, 2013; Peugny, 2014; Peregrino, 2010).

Exemplos, como o gasto financeiro associado às escolas privadas contrariamente às escolas públicas, acabam por acarretar algumas considerações no que tange ao desempenho dos alunos (Helene, 2013; Peugny, 2014). Traçando um paralelo, é possível olhar para os sujeitos que provêm de famílias que se dispõem "a pagar" por uma educação como sujeitos com boa vontade cultural e que implica, por exemplo, no investimento em uma instituição cuja estrutura escolar possua laboratórios científicos:

A boa vontade cultural exprime-se, entre outros aspectos, por uma escolha particularmente frequente dos testemunhos mais incondicionais de docilidade cultural - escolha de amigos 'instruídos', gosto por espetáculos 'educativos' ou instrutivos - muitas vezes, acompanhados por um sentimento de indignidade ('a pintura é boa, mas difícil', etc.), proporcional ao respeito concedido (Bourdieu, 2013, p. 300).

A boa vontade cultural, portanto, é caracterizada pelo reconhecimento da cultura legítima e pelo esforço sistemático para adquiri-la. Famílias da classe média e que detêm um limitado capital cultural empreenderam uma série de ações (compra de livros premiados, frequência de visitas a eventos culturais) com o intuito de aquisição de capital cultural (Nogueira \& Nogueira, 2002). 
Seria imprudente afirmar que os sujeitos provenientes das escolas da rede privada possuem desempenho melhor por conta da escola em si. Adotamos um olhar mais cuidadoso ao entender que esses alunos provêm de famílias com boa vontade cultural e, para tanto, acabam tendo maior contato com capitais de interesse à cultura científica e, justamente, performam melhor em testes tais qual o ENEM (Bourdieu \& Passeron, 2013; Krawczyk \& Silva, 2017).

A ciência, seu saber, ainda é pouco explorado como um bem importante de ser trabalhado em termos macrossociais, mas possui, a nosso ver, papel fundamental na lógica de manutenção do poder das elites na esfera nacional e que levam, hoje, a uma desigualdade atrelada ao saber científico e tecnológico (Tilly, 2006). A ciência enquanto arbitrário cultural parece indicar que o conhecimento destinado à formação dos estudantes que posteriormente estarão nas posições de poder continua negado no ensino público (não totalmente, mas em grande parte), colocando os alunos das instituições públicas em situações de descompasso, quase sempre inferior, nas disputas por vagas nos cursos consagrados e de alta seletividade (Silva et al., 2011).

O resultado dessas ações na prática aparece em proposta como os "percursos formativos" no Novo Ensino Médio, que ao passo que visam pluralizar as possibilidades formativas dos alunos, na verdade, parecem indicar impacto importante no aumento das desigualdades a longo prazo com a negação do ensino de ciências naturais aos estudantes menos privilegiados economicamente e culturalmente.

Há uma luz no fim do túnel. Ao observar os dados da pesquisa, as Ciências da Natureza parecem ser um importante meio de diminuição dessa distinção vista na perspectiva do papel desse conhecimento para o bom desempenho dos estudantes das escolas estaduais. Ainda outras análises precisam ser feitas a longo prazo para compreender sua historicidade ao longo dos últimos anos, mas pode-se observar certo alento ao defender que a ciências da natureza se caracteriza como um conhecimento marcadamente importante para garantir aos alunos das escolas públicas o acesso ao ensino superior. Valendo-se, aqui, também, da possibilidade de laboratórios científicos serem esses instrumentos mediadores da aprendizagem que podem dar suporte na formação dos estudantes. Cabe salientar, que não se pretende uma defesa unicamente pautada nos dados, mas um olhar para o questionamento sobre como as Ciências da Natureza podem ter papel importante para a diminuição da desigualdade científicotecnológica (Tilly, 2006).

\section{Conclusões e Implicações}

No presente artigo buscou-se promover uma discussão sobre o papel do conhecimento científico para a justiça social. Conforme discutido anteriormente, pretendeu-se compreender como o saber das ciências da natureza se comporta no desempenho dos alunos no ENEM e, consequentemente, na vida futura desses estudantes. Os resultados apontaram que há uma relevante discrepância entre os alunos das escolas estaduais $(n=1.050 .516)$ e privadas $(n=278.747)$ quando se observa esses grupos na faixa de acertos maiores de 600 pontos. 
As análises indicaram baixa representativa dos jovens das escolas públicas nesse intervalo de acerto, o que indica uma percepção da desigualdade social e, consequentemente, educacional, conforme apresentada pelo desempenho desses estudantes no ENEM de 2017. Enquanto 221.182 (79,34\%) dos alunos das escolas privadas pontuam acima de 600 pontos, as escolas estaduais são representadas por 434.177 candidatos (41,32\%). Como já apontam Nascimento et al. (2018) e Kleinke (2017), potencialmente, já se pode reconhecer que há indícios de que questões de ciências naturais estão se constituindo como instrumento da reprodução social e dão suporte para o reconhecimento de aspectos socioeconômicos atuantes no desempenho dos estudantes.

Ainda que o debate não se encontre finalizado, visto que se reconhece a necessidade de outros estudos que viabilizem aprofundamentos acerca dos impactos dos conhecimentos das ciências naturais na desigualdade global e regional brasileira, no comportamento dessas análises regionalmente e estudos detalhados das faixas de desempenho; os dados apontaram que o desempenho desses jovens candidatos em ciências da natureza, comparativamente, com as outras áreas do conhecimento do ENEM, é marcante no que tange à quantidade de alunos que não chegam aos 600 pontos nesse exame. São 616.339 alunos dos 1.050 .516 que possuem a média de acertos em 488 pontos, enquanto a média das instituições privadas está em 565 pontos em ciências naturais. Nesse sentido, mesmo que se reconheça e deva ser colocado em debate se toda escola privada possui qualidade educacional e se as políticas afirmativas estão dando conta de tal distinção, como as cotas para escolas públicas, é preciso mobilizar discussões que corroborem ou busquem reconhecer o papel que áreas do saber, como as linguagens, enquanto capital cultural, estão se constituindo como sinônimos de desempenho e ganho social, assim como, as ciências da natureza vêm se comportando diante de tais reflexões.

A tentativa de iniciar esse debate pode ser percebida quando alunos das escolas públicas que possuem boas pontuações têm como uma de suas características um desempenho elevado em ciências naturais ao contrário das áreas de ciências humanas. Isso não ocorre com alunos das escolas privadas analisadas, visto que os mesmos possuem desempenho mais elevado nas ciências humanas do que em ciências da natureza. Abrese espaço para a discussão do papel do capital cultural para o melhor desempenho nas ciências humanas. Isto, pois estudantes de escolas privadas, em grande parte, provêm de famílias que investem na aquisição de capital cultural possibilitando o "sucesso escolar". Em contrapartida, o impacto positivo das ciências naturais na formação dos alunos das escolas estaduais indica que o desempenho nessa área pode se constituir meio para a construção dos "espaços de possíveis" desses jovens.

Para Tilly (2006), a desigualdade científico-tecnológica enquanto instrumento geopolítico tem se mostrado cada dia mais impactante em termos das distinções e tomadas de poder das grandes corporações e governos a serviço dessas instituições capitalistas. Para Bourdieu (1994), soma-se a tal debate o papel da instituição escolar. Cabe, assim a 
defesa sobre o conhecimento científico como um dos fatores que determina as dimensões culturais que fazem parte da estrutura da classe dominante e que constantemente é negado aos que sobrevivem na periferia da sociedade e do poder político. Mobilizando tal reflexão, pode-se perceber que o conhecimento das ciências naturais não é mero saber curricular, mas instrumento de poder. De tal modo que se questiona, nesse trabalho, como o saber das ciências da natureza efetivamente pode ser reconhecido como importante para a elite cultural ou, ao menos, privilegiados economicamente, gerando e mantendo as posições de poder na sociedade. De mesmo modo, impactando o ensino público e, posteriormente, na representatividade desses estudantes em cursos de alta seletividade. Foi nesse contexto, que a análise do ENEM 2017 pode trazer algumas reflexão para mobilizar indicativos de seu papel na desigualdade científico-tecnológica e para a justiça social, buscando reconhecer seu papel para a construção de propostas que visem dar suporte na compreensão das Ciências da Natureza na formação dos alunos e na construção de uma sociedade mais justa.

\section{Referências}

Alves, T., \& Pinto, J. M. R. (2011). Remuneração e características do trabalho docente no Brasil: um aporte. Cadernos de Pesquisa, 41(143), 606-639. https://doi.org/10.1590/ S0100-15742011000200014

Archer, L., Dawson, E., DeWitt, J., Seakins, A., \& Wong, B. (2015). "Science Capital": a conceptual, methodological, and empirical argument for extending bourdieusian notions of capital beyond the Arts. Journal of research in science teaching, 52(7), 922948. https://doi.org/10.1002/tea.21227

Bastos, R. M. B. (2017). O surpreendente êxito do sistema educacional finlandês em um cenário global de educação mercantilizada. Revista Brasileira de Educação, 22(70), 802-825. https://doi.org/10.1590/S1413-24782017227040

Bourdieu, P., \& Passeron, J. C. (2014). Os herdeiros: os estudantes e a cultura (2a ed.). UFSC.

Bourdieu, P. (2004). Os usos sociais da ciência: por uma sociologia clínica do campo científico.UNESP.

Bourdieu, P. (2003). O campo científico. In S. Miceli (Org.), A sociologia de Pierre Bourdieu (pp. 122-155). Olho D’água.

Bourdieu, P. (1994). Razões Práticas: Sobre a teoria da ação. Papirus.

Bourdieu, P. (2001). Para uma sociologia da ciência. Edições 70.

Bourdieu, P. (2011). O senso prático ( $3^{\mathrm{a}}$ ed.). Vozes.

Bourdieu, P. (2013). A distinção: crítica social do julgamento (2a ed.). Zouk.

Bourdieu, P., \& Passeron, J. C. (2013). Os herdeiros: Os estudantes e a cultura. UFSC. 
Bourdieu, P., \& Wacquant, L. (1992). Réponses. Seuil.

Claussen, S., \& Osborne, J. (2012). Bourdieu's notion of cultural capital and its implications for the science curriculum. Science Education, 97(1), 58-79. https://doi. org/10.1002/sce.21040

Costa-Beber, L. B. C., Maldaner, O. A., Pansera-de-Araújo, M. C. P., \& Gehlen, S. T. (2014). Processos seletivos de Universidades Públicas da Região Sul do Brasil: movimento de mudanças a partir do Novo ENEM. Revista Brasileira de Pesquisa em Educação em Ciências, 14(1), 217-232. https://periodicos.ufmg.br/index.php/rbpec/article/view/4289 Cunningham, F. (2002). Teorias da democracia: uma introdução crítica. ArtMed.

Delizoicov, D., \& Auler, D. (2011). Ciência, tecnologia e formação social do espaço: questões sobre a não-neutralidade. Alexandria: Revista de Educação em Ciência e Tecnologia, 4(2) 247-273. https://periodicos.ufsc.br/index.php/alexandria/article/ view/37690

Duru-Bellat, M., \& Van Zanten, A. (2009). Sociologie du système éducatif: Les inégalités scolaires. Puf.

Ferreira, E. A. (2018). Teoria de Resposta ao Item - TRI: Análise de algumas questões do ENEM - habilidades 24 a 30 (Dissertação de Mestrado, Universidade Federal da Grande Dourados, Dourados, Mato Grosso do Sul). Repositório Institucional - UFGD. https://repositorio.ufgd.edu.br/jspui/handle/prefix/1258

Ferrara, J. L. (2011). A pesquisa educacional crítica pode ser "quantitativa"? In M. Apple, A.U., Wayne \& L. A. Gandin (Orgs.), Educação crítica: Análise Internacional (pp. 512529). Artmed.

Forquin, J. C. (1993). A escola e a cultura: a sociologia do conhecimento escolar. Artes Médicas.

Fundação Abrinq (2019). Agenda Legislativa. https://observatoriocrianca.org.br/ agenda-legislativa

Gramani, M. C. (2017). A desigualdade socioeconômica afeta mais municípios menos favorecidos?. Cadernos de Pesquisa, 47(164), 470-494. https://doi. org/10.1590/198053144220

Gurgel, I., \& Watanabe, G. (2020). The Writing of the History of Science from the Notion of Scientific Field. Transversal: International Journal for The Historiography of Science, 8(1), 41-58. https://doi.org/10.24117/2526-2270.2020.i8.05

Helene, O. (2013). Um diagnóstico da educação brasileira e de seu financiamento. Autores Associados.

Kleinke, M. U. (2017). Influência do status socioeconômico no desempenho dos estudantes nos itens de física do ENEM 2012. Revista Brasileira de Ensino de Física, 39(2), e2402. https://doi.org/10.1590/1806-9126-RBEF-2016-0081 
Krawczyk, N., \& Silva, C. J. O. (2017). Desigualdade educacionais no ensino médio brasileiro: uma análise do perfil socioeconômico de jovens que realizam o Exame Nacional do Ensino Médio. Senso-E, 4(1), 12-23. https://doi.org/10.34630/sensos-e. v4i1.2253

Libâneo, J. C. (2012). O dualismo perverso da escola pública brasileira: escola do conhecimento para os ricos, escola do acolhimento social para os pobres. Educação \& Pesquisa, 38(1) 13-28. https://doi.org/10.1590/S1517-97022011005000001

Lima Junior, P., Ostermann, F., \& Rezende, F. (2013). Análise dos condicionantes sociais do sucesso acadêmico em cursos de graduação em física à luz da sociologia de Bourdieu. Ensaio Pesquisa em Educação em Ciências, 15(1), 113-129. https://doi.org/10.1590/198321172013150108

Marguti, B. O., Costa, M. A., \& Pinto, C. V. S. (2017). Territórios em números: Insumos para políticas públicas a partir da análise do IDHM e do IVS de municípios e unidades da federação brasileira. Ipea. https://www.ipea.gov.br/portal/images/stories/PDFs/livros/ livros/170828_territorios_em_numeros_1.pdf

Montagner, M. A., \& Montagner, M. I. (2011). A teoria geral dos campos de Pierre Bourdieu: uma leitura. Tempus - Actas de Saúde Coletiva, 5(2), 255-273. https://www. tempusactas.unb.br/index.php/tempus/article/view/979

Morley, L. (2013). Ímpeto e melancolia. As mulheres no ensino superior internacionalmente. In M. Apple, S. Ball, \& L. A. Gandin (Orgs.), Sociologia da Educação: análise internacional (pp. 416-427). Penso.

Nascimento, M. M., Cavalcanti, C., \& Ostermann, F. (2018). Na busca por questões de Física do ENEM potencialmente não reprodutoras das desigualdades socioeconômica. Revista Brasileira de Ensino de Física, 40(3), e3402. https://doi.org/10.1590/1806-9126RBEF-2017-0237

Nascimento, M. M. (2019). O acesso ao ensino superior público brasileiro: um estudo quantitativo a partir dos microdados do Exame Nacional do Ensino Médio (Tese de Doutorado, Universidade Federal do Rio Grande do Sul, Porto Alegre, Rio Grande do Sul). Lume - Repositório Digital (UFRGS). http://hdl.handle.net/10183/188431

Nascimento, M. M., Lima, N. W., Cavalcanti, C. J. H., \& Ostermann, F. (2019). Cultura política, desempenho escolar e a Educação em Ciências: um estudo empírico à luz de Pierre Bourdieu. Ciência \& Educação, 25(2), 431-447. https://doi.org/10.1590/1516731320190020010

Neves, F. M. (2015). Bíos e Techné. Estudo sobre a construção do sistema de biotecnologia periférico. Editora UnB.

Nogueira, C. M. M., \& Nogueira, M. A. (2002). A sociologia da educação de Pierre Bourdieu: Limites e Contribuições. Educação \& Sociedade, 23(78), 15-35. https://doi. org/10.1590/S0101-73302002000200003 
Peregrino, M. (2010). Trajetórias desiguais: Um estudo sobre os processos de escolarização pública de jovens pobres. Garamond.

Peugny, C. (2014). O destino vem do berço? Desigualdades e reprodução social. Papirus.

Pires, A. (2015). Renda familiar e escolaridade dos pais: reflexões a partir dos microdados do ENEM 2012 do Estado de São Paulo. Educação Temática Digital, 17(3), 535-541. https://doi.org/10.20396/etd.v17i3.8638262

Rocha, M., \& Perosa, G. S. (2008). Notas etnográficas sobre a desigualdade educacional brasileira. Educação \& Sociedade, 29(103), 425-449. https://doi.org/10.1590/S010173302008000200007

Sapiro, G. (2004). Elementos para uma história do processo de autonomização: o exemplo do campo literário francês. Tempo Social, 16(1), 93-105. https://doi.org/10.1590/S010320702004000100005

Setton, M. G. J. (2011). Teoria da socialização: um estudo sobre relações entre indivíduo e sociedade. Educação e Pesquisa, 37(4),711-724. https://doi.org/10.1590/S151797022011000400003

Silva, A., Ney, M. G., \& Caetano, R. C. (2011). Desigualdades de oportunidades educacionais reveladas pelo ENEM no estado do Rio de Janeiro. Agenda Social, 5(1), $43-64$.

Silva, E., \& Wright, D. (2008). Researching cultural capital: complexities in mixing methods. Methodological Innovations Online, 2(3), 50-62. https://doi.org/10.4256/ mio.2008.0005

Silva, L. M., \& Barbosa, R. C. (2019). Aspectos sociais na escolha pela licenciatura em física: uma análise em universidades do Rio Grande do Sul. Ensaio Pesquisa em Educação em Ciências, 21, e10544. https://doi.org/10.1590/1983-21172019210112

Tilly, C. (2006). O acesso desigual ao conhecimento científico. Tempo Social, 18(2), 4763. https://doi.org/10.1590/S0103-20702006000200003 
${ }^{\circ}$ Diego Navarro

Universidade Federal do $A B C$

Bangú, Santo André, São Paulo diego.navarro@aluno.ufabc.edu.br

Matheus lanello

Universidade Federal do $A B C$

Bangú, Santo André, São Paulo matheus.ianello@aluno.ufabc.edu.br

Felipe Muneratto

Universidade Federal do $A B C$

Bangú, Santo André, São Paulo

felipe.muneratto@aluno.ufabc.edu.br

Graciella Watanabe

Universidade Federal do $A B C$ Bangú, Santo André, São Paulo graciella.watanabe@ufabc.edu.br

Editor Responsável

Alessandro Damásio Trani Gomes

Manifestação de Atenção às Boas Práticas Científicas e de Isenção de Interesse

Os autores declaram ter cuidado de aspectos éticos ao longo do desenvolvimento da pesquisa e não ter qualquer interesse concorrente ou relações pessoais que possam ter influenciado o trabalho relatado no texto. 